\title{
Sber ecosystem - the product of digitalization impact on intersectoral economic convergence
}

\author{
G. Chernova ${ }^{1 *}$, S. Kalayda ${ }^{1}$, V. Khalin ${ }^{1}$, A. Yurkov ${ }^{1}$ \\ 1 Saint Petersburg State University, Saint Petersburg, Russia \\ *g.chernova@spbu.ru
}

\begin{abstract}
The article contains the study of the experience of operation of the specific Sber financial ecosystem as a new form of entrepreneurial activity in the competitive economic environment which is driven by the impact of digitalization on the economic convergence processes - the modern trend in the social development in general. The study of the experience of the Sber financial ecosystem which is one of the most highly developed ones in Russia is both of theoretical and practical interest. The purpose of the article is to describe the actual experience of Sber ecosystem's operation. The results of the performed analysis are as follows. Definitely the Sber ecosystem is a form of organization of joint business implemented in the framework of intersectoral convergence driven by digitalization. The impact of intersectoral convergence is manifested in the fact that the creation of the ecosystem was initiated by a financial institution - the largest Russian savings bank; and the participants in this ecosystem are representatives of a wide variety of sectors and segments of the economy. The impact of digitalization shows in the fact that the basis of joint business is a modern digital base which includes IT, IT platforms and networks. The modern mathematical and instrumental methods of data processing and IT startups are not only the digital specifics of the ecosystem functioning, but also effective tools to attract to a joint business - on a voluntary basis only - the partners from various fields of activity, and provide the Sber ecosystem with undoubted competitive advantages.
\end{abstract}

Keywords: intersectoral financial convergence, digitalization, financial ecosystem "Sber", ecosystem activities parameters, business conduct IT-base, mathematical and instrumental methods, startups

For citation: Chernova G., Kalayda S., Khalin V., Yurkov A. Sber ecosystem - the product of digitalization impact on intersectoral economic convergence. Prikladnaya informatika=Journal of Applied Informatics, 2021, vol.16, no.3, pp.57-68. DOI: 10.37791/2687-0649-2021-16-3-57-68 